\title{
A gamificação como aliada no processo de produção textual
}

\author{
Gamification as an ally of the text production process
}

\author{
Fábia Magali Santos Vieira** \\ Rosângela Soares dos Santos Souza ${ }^{* *}$
}

\begin{abstract}
RESUMO: Neste artigo, apresentamos uma pesquisa em andamento, na qual buscamos analisar as contribuições da gamificação no desenvolvimento de habilidades de escrita de textos narrativos. Embora a narração seja uma tipologia muito abordada nas aulas de língua materna, observamos que persistem dificuldades em relação à estrutura dos textos e, além disso, engajar os estudantes nas atividades propostas tem se constituído um desafio constante para os professores. Defendemos a hipótese de que a gamificação, aplicada ao contexto educacional, é uma estratégia capaz de motivar a participação dos estudantes nas atividades de sala de aula. Como embasamento teórico, adotamos as concepções de texto e produção textual (BRASIL, 1998; MINAS GERAIS, 2008; MARCUSCHI, 2008), sequência narrativa (BRONCKART, 2012), letramento digital (XAVIER, 2005) e gamificação (SCHLEMMER, 2014; VIANNA et al., 2013; FARDO, 2013). Quanto aos procedimentos técnicos, a pesquisa está sendo desenvolvida na perspectiva da pesquisa-ação, buscando a reflexão sobre a prática pedagógica, com o objetivo de intervir, a partir de embasamento teórico, nos problemas identificados, minimizando-os.
\end{abstract}

PALAVRAS-CHAVE: Gamificação. Produção de textos. Narrativa.

\begin{abstract}
In this paper we present an ongoing study, in which we analyze the contributions of gamification to the development of writing skills in the production of narrative texts. Although the narrative typology has been widely approached in mother tongue classes, difficulties remain in coping with text structure and engaging students in the activities. We defend the hypothesis that using gamification at school is a strategy to motivate students' participation in classroom activities. As a theoretical basis, we adopt the notions of text and text production (BRASIL, 1998; MINAS GERAIS, 2008; MARCUSCHI, 2008), narrative sequence (BRONCKART, 2012), digital literacy (XAVIER, 2005), and gamification (SCHLEMMER, 2014; VIANNA et al., 2013; FARDO, 2013). The technical procedures are built on action research, aiming at using theoretical background and reflecting upon the pedagogical practice to overcome problems and minimize them.
\end{abstract}

KEYWORDS: Gamification. Text production. Narrative.

\section{Introdução}

Nas últimas décadas, a disseminação de novas tecnologias digitais provocou grandes transformações na vida das pessoas. Em plena era digital, os games tornaram-se uma forma de entretenimento muito popular, principalmente entre os adolescentes. Observar o crescente fascínio que os games exercem sobre as pessoas nos leva a refletir: os games podem

\footnotetext{
* Doutora em Educação FE/UnB. Professora e pesquisadora da Universidade Estadual de Montes Claros (Unimontes). Coordenadora de subprojeto do curso de Pedagogia PIBID/Unimontes. Docente do Mestrado Profissional em Letras (PROFLETRAS) - Unimontes.

${ }^{* *}$ Mestranda do curso de Mestrado Profissional em Letras - Unimontes. Professora da rede pública estadual de Minas Gerais.
} 
influenciar de forma positiva o modo de pensar e agir dos indivíduos? Nesse sentido, encontramos em Fardo (2013) a afirmação de que, de fato, alguns métodos e elementos presentes nos games são capazes de proporcionar aprendizagens úteis em vários domínios da vida, de forma eficiente e prazerosa.

É nesse contexto que surge o conceito recente de gamificação, que consiste em aplicar os elementos, dinâmicas, estilo e pensamentos de games a um contexto exterior aos games. Assim, entendemos que gamificar significa conhecer e analisar os elementos presentes em jogos, capazes de divertir e engajar os sujeitos, e adaptar esses elementos a situações que normalmente não são consideradas jogos, como na aprendizagem.

Diferentemente do que ocorre com os games, nossa experiência em sala de aula, como professores de língua materna, tem nos mostrado o desinteresse de grande parte dos alunos pelas atividades de produção de textos. Foi na busca por estratégias de engajamento nessas atividades que nos propusemos a investigar as contribuições da gamificação no desenvolvimento de habilidades de escrita de textos. Elegemos a produção de textos do tipo narrativo como alvo do nosso trabalho, pois verificamos que, apesar de ser um tipo textual muito comum na escola, ainda existem dificuldades para escrever narrativas com sequência temporal, elementos de conflito, caracterização de personagens, clímax e, principalmente, desfechos coerentes com o processo narrativo desenvolvido.

Lançamos mão da gamificação por ser uma estratégia que, no contexto educacional, pode motivar a participação ativa dos estudantes nas atividades de sala de aula. Nesta proposta, a gamificação se concretizou através da nossa ação de transformar os conteúdos que envolvem a estrutura narrativa em jogos digitais.

A pesquisa sobre a qual discorremos neste trabalho está situada na área de linguagens e letramentos, inserida na linha de pesquisa "leitura e produção textual: diversidade social e práticas docentes", do Mestrado Profissional em Letras (PROFLETRAS) da Universidade Estadual de Montes Claros. Para a construção do aporte teórico, adotamos as concepções de texto e produção textual (BRASIL, 1998; MINAS GERAIS, 2008; MARCUSCHI, 2008), sequência narrativa (BRONCKART, 2012), letramento digital (XAVIER, 2005) e gamificação (SCHLEMMER, 2014; VIANNA et al., 2013; FARDO, 2013).

\section{0 texto como unidade de ensino, a gamificação e o letramento digital na sala de aula}

De acordo com Rojo e Cordeiro (2004, p. 7), "não é de hoje que circula e é aceita, no Brasil, a ideia de que o texto [...] é a base do ensino-aprendizagem de Língua Portuguesa". 
Essa concepção começou a ser preconizada no país, ao menos teoricamente, a partir da década de 1980, com o surgimento de algumas propostas curriculares que recomendavam que o ensino de língua materna ocorresse por meio dos textos.

Até então, o texto era visto como um material que possibilitava atividades de análise linguística, leitura e escrita. Embora ocupando lugar central no ensino da língua, o texto se constituía objeto de uso, e não de ensino. A produção textual era resultado do estímulo proporcionado pelo hábito de leitura de bons textos, pois se concebia a ideia de que, através da leitura, o aluno seria capaz de aprender estratégias diversas que poderiam ser utilizadas no planejamento, revisão e editoração do seu próprio texto, no momento da escrita.

No entanto, mesmo tomando como modelo os textos consagrados pelo cânone, o ensino da escrita proposto pela escola acabou por instituir "verdadeiros objetos escolares para o ensino da composição, que vão se transformando em textos exclusivamente escolares, sem qualquer referência textual extraescolar" (SANTOS, 2007, p. 14). Dessa maneira, com a ênfase no ensino das propriedades estruturais dos textos, surgiram os chamados gêneros escolares por excelência: a descrição, a narração e a dissertação.

Para Rojo e Cordeiro (2004, p. 9), com a abstração do contexto de produção e circulação dos textos, concebiam-se uma "leitura de extração de informações (explícitas e implícitas) mais do que uma leitura interpretativa, reflexiva e crítica, e uma produção guiada pelas formas e pelos conteúdos mais que pelo contexto e pelas finalidades dos textos". Percebe-se que o texto servia apenas como pretexto para o ensino das normas gramaticais, já que era visto como um conjunto de unidades linguísticas (palavras, frases, períodos) organizadas para a expressão do pensamento.

A partir da década de 1990, houve uma mudança no enfoque dado ao texto e seu uso em sala de aula. O contexto de produção e circulação dos textos fica em evidência, bem como seu funcionamento e sentidos gerados e, em segundo plano, as suas propriedades formais. Essa proposta ganha força a partir da implantação dos Parâmetros Curriculares Nacionais (BRASIL, 1998), os PCN, que propõem o ensino de língua por meio dos gêneros textuais, visando à preparação dos alunos para uma participação ativa na atual sociedade, cada vez mais letrada e tecnológica.

Na concepção dos PCN (1998), o ensino comprometido com o pleno exercício da cidadania precisa oferecer condições para que os seus estudantes desenvolvam competências discursivas. Dessa maneira, cabe à escola o dever de promover atividades curriculares que 
priorizem o texto no processo de ensino-aprendizagem da língua e da linguagem, sempre com o objetivo de capacitar o aluno, que é sujeito social, "a utilizar a língua de modo variado, para produzir diferentes efeitos de sentido e adequar o texto a diferentes situações de interlocução oral e escrita" (BRASIL, 1998, p. 23).

Para um trabalho pautado nessa concepção, não é produtivo eleger como "unidades básicas do processo de ensino as que decorrem de uma análise de estratos [...] que, descontextualizados, são normalmente tomados como exemplos de estudo gramatical e pouco têm a ver com a competência discursiva" (BRASIL, 1998, p. 23). Nessa perspectiva, a unidade básica do ensino deve ser o texto.

Embora haja consenso quanto à centralidade do texto no ensino de língua, existem muitos problemas a serem superados. Marcuschi (2008, p.52) alerta que não devemos imaginar "que o trabalho com o texto tenha virtudes imanentes naturais, a ponto de se tornar uma espécie de panaceia geral para todos os problemas de língua”.

Entendemos que são muitas as formas de trabalhar textos, que dispõem de uma gama de potencialidades a serem exploradas quanto ao ensino da língua. Contudo, Marcuschi (2008) afirma que o texto ainda recebe uma abordagem inadequada e até desastrosa nas salas de aula, apesar dos vários estudos e pesquisas desenvolvidas nessa área.

\subsection{Produção de textos na escola}

Tendo em vista a relevância de trabalhar o texto como unidade central do ensino de língua materna, é preciso atentar ao fato de que o processo de produção escrita não pode ser visto meramente como um exercício escolar, como ocorre muitas vezes. A escola deve levar o aluno a perceber que a escrita é um objeto social, imprescindível na organização e manutenção da sociedade, pois, conforme afirma Marcuschi (2008, p. 72), o texto "refrata o mundo na medida em que o reordena e reconstrói”.

O reconhecimento da função social do texto possibilita que o sujeito-leitor se aproprie dos propósitos comunicativos do autor do texto e, na condição de produtor, pode situar com propriedade seu "projeto de dizer" (PASSARELI, 2012, p. 129). A função social dos textos pode se desdobrar, basicamente, em uma função estética, de entreter, elogiar, sensibilizar, provocar prazer, mas também em uma função utilitária, de informar, formar opinião, explicar, argumentar.

De acordo com os PCN (BRASIL, 1998), no planejamento de atividades para ensinar a escrever, é preciso considerar os múltiplos aspectos envolvidos na produção de textos, para 
propor sequências de atividades que diminuam a complexidade da tarefa, no que se refere tanto ao processo de escrita quanto ao de revisão do próprio texto. Inicialmente, podem ser propostas atividades que envolvam reproduções, paráfrases ou resumos, pois, com o plano do conteúdo já definido pelo texto modelo, o aluno não terá dificuldades com o que escrever. A atividade oferece possibilidades de se tratar de aspectos coesivos da língua, de aspectos do plano da expressão, o como dizer. Já as atividades de produção em que o aluno é o criador do próprio texto são mais complexas, porque é preciso articular ambos os planos: o do conteúdo e o da expressão. Para a análise desses textos, o olhar do professor precisa deslocar-se da correção para a interpretação; do levantamento das faltas cometidas para a apreciação dos recursos que o aluno já consegue manobrar (BRASIL, 1998).

\subsection{A sequência narrativa em foco}

Quanto aos textos narrativos, foco do nosso trabalho, o Conteúdo Básico Comum (MINAS GERAIS, 2008), o CBC, para o Ensino Fundamental, estabelece, no tópico 8, a habilidade principal: reconhecer e usar, de forma produtiva e autônoma, estratégias de textualização do discurso narrativo, na compreensão e na produção de textos. No referido tópico, o CBC orienta, dentre outros, o trabalho com os seguintes conteúdos:

Textualização do discurso narrativo (ficcional)

- Fases ou etapas:

- exposição ou ancoragem (ambientação da história, apresentação de personagens e do estado inicial da ação);

- complicação ou detonador (surgimento de conflito ou obstáculo a ser superado);

- clímax (ponto máximo de tensão do conflito);

- desenlace ou desfecho (resolução do conflito ou repouso da ação; pode conter a avaliação do narrador acerca dos fatos narrados e, ainda, a moral da história). (MINAS GERAIS, 2008, p. 40)

Esse documento estabelece algumas habilidades específicas relacionadas ao trabalho com o texto e sequências narrativas, dentre as quais selecionamos a habilidade 8.1 (reconhecer e usar as fases ou etapas da narração em um texto ou sequência narrativa) como alvo da nossa proposta de intervenção.

Bronckart (2012) afirma que o eixo central da organização de uma sequência narrativa é o processo de intriga. Para formar uma história, os acontecimentos devem estar organizados de maneira que a ação seja completa, com início, meio e fim. Um "todo acional dinâmico", postulado pelo autor, inicia-se com um estado de equilíbrio; surge então uma tensão, a partir da qual se desencadeia uma ou várias transformações, no fim das quais emerge um novo 
estado de equilíbrio (BRONCKART, 2012). Assim, um protótipo simples para a sequência narrativa pode ser resumido pela articulação de três fases: situação inicial, transformação e situação final.

Vários modelos de sequência narrativa foram propostos por teóricos. Entretanto, é a partir de Labov e Waletzky ${ }^{1}$ (1967 apud BRONCKART, 2012) que se consolida um protótipo padrão, composto de cinco fases principais, assim dispostas:

- situação inicial: momento de apresentação de um estado de equilíbrio, no qual será inserida uma perturbação;

- complicação: fase em que se introduz exatamente a perturbação e a tensão é iniciada;

- ações: fase que abarca os acontecimentos desencadeados pela tensão;

- resolução: momento em que são introduzidos os acontecimentos que resultarão na redução da tensão; e

- situação final: surgimento de um novo estado de equilíbrio, obtido pela fase de resolução.

Bronckart (2012) acrescenta a essas cinco fases principais outras duas, mais diretamente dependentes do posicionamento e perspectiva do narrador em relação aos fatos narrados. São elas:

- avaliação: momento em que se emite um parecer ou comentário sobre o desenvolvimento da história;

- moral: fase de explicitação da significação global atribuída aos acontecimentos, geralmente posicionada no início ou fim da sequência.

Em razão do propósito comunicativo, da escolha do gênero textual adequado e das opções feitas pelo produtor de um texto, as sequências narrativas, efetivamente, podem variar muito. Enquanto alguns textos comportam todas as fases supracitadas, outros podem ser compostos por um número reduzido de fases (apenas situação inicial, complicação e resolução).

\subsection{Gamificação no contexto educacional}

Embora a palavra gamificação seja um termo recente, as estratégias que ela condensa não são exatamente uma novidade. Esse termo foi introduzido em 2008 pela indústria de

\footnotetext{
${ }^{1}$ LABOV, W.; WALETZKY, J. Narrative analyses: oral versions of personal experiences. In: HELM, J. (Ed.). Essays on the verbal and visual arts. Seattle: University of Washington Press, 1967.
} 
mídias digitais e ganhou popularidade a partir de 2010, sendo largamente utilizado em várias áreas, inclusive na educação. De acordo com Vianna et al. (2013, p. 13), “a gamificação (do original em inglês, gamification) corresponde ao uso de mecanismos de jogos orientados ao objetivo de resolver problemas práticos ou de despertar engajamento entre um público específico". Gamificar consiste em aplicar os elementos, dinâmicas, estilo e pensamentos de games a um contexto exterior aos games. Na concepção de Schlemmer (2014, p. 77), “a gamificação se ocupa, então, de analisar os elementos presentes no design de jogo, que fazemno ser divertido, e adaptar esses elementos a situações que normalmente não são consideradas jogos."

Compreendemos que elementos, mecanismos, design e dinâmicas de jogos dizem respeito, por exemplo, a lançamento de desafios, cumprimento de regras, metas claras e bem definidas, efeito surpresa, conquista de pontos e troféus, interatividade, superação de níveis, criação de avatares (termo utilizado por internautas e jogadores de videogame para designar a personificação imaginária da própria pessoa e do seu estado de espírito na forma de um personagem), estabelecimento de jornadas e missões a serem cumpridas, dentre outras estratégias. Já o contexto exterior aos games abrange situações diferentes dos campos de jogo usuais, ou seja, são situações pertencentes à realidade do dia a dia profissional, escolar e social do indivíduo.

A gamificação não se limita ao uso de apenas um ou outro elemento citado, mas deve ser concebida como o imbricamento de diversos desses fatores, para alcançar o engajamento das pessoas envolvidas. Kapp (2012) afirma que o pensamento baseado em estrutura e dinâmica de jogos se configura no elemento central da gamificação, capaz de transformar uma atividade rotineira em uma atividade gamificada, que agrega competição, cooperação e narrativa instigadora. O ponto essencial é a ideia de tornar determinado contexto ou situação em uma espécie de jogo, ao incorporar elementos que tornam os games experiências agradáveis e prazerosas.

No contexto educacional, de acordo com Fardo (2013, p. 65), o que a gamificação propõe é "utilizar um conjunto de elementos comumente encontrados na maioria dos games e aplicá-los nesses processos, com o intuito de gerar níveis semelhantes de envolvimento e dedicação daqueles [sic] que os games normalmente conseguem gerar”. Nesse sentido, Schlemmer (2014) aponta duas perspectivas para se pensar a gamificação no contexto da educação. A primeira é a perspectiva epistemológica empirista, em que se utiliza a 
gamificação como estratégia de persuasão, estimulando a competição, através de um sistema de pontuação, de recompensa, de premiação, dentre outros. A outra perspectiva é a epistemológica interacionista-construtivista-sistêmica, em que a aprendizagem pode ser vista como "construção colaborativa e cooperativa, instigada por desafios, missões, descobertas, empoderamento em grupo" (SCHLEMMER, 2014, p. 77). O interacionismo-construtivista de Jean Piaget considera a ação do sujeito elemento primordial para a aprendizagem, que é provocada por situações exteriores. A aprendizagem se dá por meio da interação entre o indivíduo e o objeto, num processo de assimilação ativa. É nessa perspectiva que guiamos nossa proposta de intervenção.

A gamificação, aplicada aos ambientes de aprendizagem, pode afetar tanto o processo de ensino quanto o de aprendizagem. É uma estratégia que motiva o desenvolvimento da autonomia do aluno; assim, o professor deixa de ser aquele que transmite o conhecimento e o único que detém o saber. O estudante, ao aprender a buscar o conhecimento, pode trazer situações que estão "fora do controle do professor", ou seja, são desconhecidas para ele. Dessa maneira, a sala de aula pode se configurar como um ambiente realmente interativo, de troca de conhecimentos entre alunos e também entre alunos e professores.

\subsection{Letramento digital}

Segundo Kleiman (2005), assim como a língua passou por transformações ao longo dos anos, a concepção do que é necessário saber para usar a escrita também foi alterada. As novas tecnologias digitais, que dão suporte aos usos da língua escrita, têm provocado muitas mudanças, inclusive na escola. Hoje, espera-se que o aluno seja letrado, ou seja, além de dominar o código, precisa saber compreender e se comunicar, por meio da escrita, numa variada gama de situações, incluindo a internet.

Em um contexto de ampla disseminação de novas tecnologias de informação e comunicação, pesquisadores visualizam o surgimento de um novo modo de letramento, o letramento digital. De acordo com Xavier (2005, p. 2), mesmo que um indivíduo seja alfabetizado e letrado, é possível que seja um "analfabeto ou iletrado digital", uma vez que o letramento digital implica dominar práticas de leitura e escrita diferentes das formas tradicionais de alfabetização e letramento. Para ser letrado digital, o indivíduo deve ser capaz de ir além do manuseio técnico das novas tecnologias. É necessário:

... assumir mudanças no modo de ler e escrever os códigos e sinais verbais e não verbais, como imagens e desenhos, se compararmos às formas de leitura 
e escrita feitas no livro, até porque o suporte sobre o qual estão os textos digitais é a tela, também digital. (XAVIER, 2005, p. 2)

De acordo com o autor, o domínio do letramento alfabético é uma das condições para a aquisição do letramento digital, uma vez que existe uma relação de dependência entre o "novo" tipo de letramento e o "velho". Essa relação entre os dois tipos de letramento evidencia a importância e amplia o uso do letramento alfabético em razão da chegada do digital. Apenas o indivíduo letrado alfabético terá condições de adquirir o letramento digital.

O letramento digital introduz um novo modo de realizar as atividades de leitura e escrita, ao passo que possibilita uma série de vantagens ao usuário das tecnologias digitais, dentre as quais podem ser citadas: maior agilidade na apreensão, gerenciamento e compartilhamento de informações, verificação da autenticidade de determinados dados, ampliação do dimensionamento da significação das palavras e produção de textos em coautoria com outros interlocutores, de modo simultâneo, com ferramentas on-line.

\section{Percurso metodológico}

Nesta seção, apresentamos os procedimentos metodológicos e resultados parciais da pesquisa em questão, que possui natureza aplicada e cunho qualitativo. Quanto aos procedimentos técnicos, a pesquisa - aprovada sob o Parecer No. 1.520.231 do Comitê de Ética em Pesquisa com Seres Humanos - está sendo desenvolvida na perspectiva da pesquisaação, buscando a reflexão sobre a prática pedagógica, com o objetivo de intervir, a partir de embasamento teórico, nos problemas identificados, sanando-os ou, ao menos, minimizandoos.

Entendemos que o papel ativo do pesquisador na resolução dos problemas identificados e como o acompanhamento e avaliação das ações desencadeadas em função dos problemas são características primordiais da pesquisa-ação, que exige uma relação participativa entre pesquisadores e indivíduos envolvidos na situação em estudo. Na presente pesquisa, observamos todos esses requisitos; portanto, podemos afirmar que realizamos uma pesquisa-ação participante, que se encontra em fase de análise dos dados coletados.

A coleta de dados foi realizada através da observação participante e aplicação de atividades em sala de aula, em uma turma do $9^{\circ}$ ano do Ensino Fundamental, de uma escola pública de Montes Claros/MG. Para isso, foi elaborado um Projeto Educacional de Intervenção, cujo objetivo principal consistiu em promover o desenvolvimento de habilidades relacionadas à produção de textos narrativos através da gamificação. 
Para a execução das atividades, previstas na referida proposta de intervenção, adotamos a teoria denominada "Metáforas para o aprendizado no século XXI", desenvolvida por Thornburg (1996). Essa teoria defende que os ambientes cognitivos e afetivos são essenciais para o processo de ensino-aprendizagem. $\mathrm{O}$ autor apresenta um paralelo entre as formas de transmissão/aquisição do conhecimento dos antigos povos e da sociedade contemporânea, ao propor as metáforas da fogueira, do poço d'água, da caverna e da vida. A partir dessas metáforas, organizamos as atividades propostas em quatro módulos, denominados conhecendo, dialogando, refletindo e praticando.

De acordo com Thornburg (1996), tudo se inicia com a reunião em torno da fogueira, momento de transmissão do conhecimento e sabedoria dos mais antigos aos mais jovens, através do ato de contar histórias. Definimos como o módulo conhecendo esse momento de exposição do mestre para os aprendizes, não como transmissor apenas, e sim como mediador da construção do conhecimento. A metáfora do poço d'água faz referência ao momento de busca coletiva por esse precioso recurso natural e as relações sociais estabelecidas no percurso, com as conversas rotineiras e a difusão de informações. Em nossa proposta, definimos como dialogando o momento em que os aprendizes tiveram oportunidade de dialogar, discutir e trocar conhecimentos entre si e também com o mestre, numa perspectiva sociointerativa de ensino-aprendizagem.

Através da metáfora da caverna, o autor nos remete a momentos de introspecção, com o recolhimento na caverna, para a reflexão. A essa metáfora relacionamos o módulo refletindo, cujas atividades proporcionaram ao aprendiz um trabalho individualizado, para a reflexão sobre tudo o que foi ensinado e discutido. A última metáfora é a da vida, que se refere à participação ativa e ao desenvolvimento prático de conhecimentos adquiridos. Definimos como o módulo praticando a etapa final, em que o aprendiz teve a oportunidade de aplicar os conhecimentos adquiridos e experimentá-los na prática.

Essa metodologia possibilitou a organização das atividades de forma a proporcionar maior participação dos estudantes. O aluno pôde vivenciar cada etapa e, passo a passo, desenvolver sua criatividade e imaginação, favorecendo a produção de textos. $O$ conhecimento, a partir dessa metodologia, é construído na relação aluno-professor e também, mais significativamente, na interação aluno-aluno. 


\subsection{Descrição das atividades desenvolvidas no Projeto Educacional de Intervenção}

\subsubsection{Módulo 1: Conhecendo}

Nossa proposta de intervenção partiu do contato e reflexão sobre o texto narrativo por meio da gamificação. Nesse sentido, desenvolvemos o jogo "Uma aventura em outro mundo", para ser jogado on-line, disponível em: <http://www.fpsouza.com.br/projetos/rosangela/>. Com o enredo presente no jogo, os alunos puderam aprender os elementos constitutivos de uma narrativa (enredo, personagens, tempo, espaço e narrador) e, ao final, produziram um texto narrativo, ainda no ambiente do jogo. Esse texto integra os corpora da pesquisa. Utilizamos a técnica da predição para a apresentação de textos narrativos, relacionando-os com as perguntas essenciais para identificação dos elementos da narrativa. Foram estudados tais elementos e as fases constitutivos de uma narrativa, conforme estabelece o CBC, através da análise de textos variados.

Nesse módulo, as atividades de aprendizagem estiveram centradas na interação mestre-aprendiz, por ser um momento inicial de discussão do conteúdo. Os alunos foram estimulados a participar ativamente de todo o processo. Para este módulo, desenvolvemos também um jogo, denominado Detetive Expert, no qual os alunos liam várias versões de uma mesma história e identificavam o narrador adequado entre as possibilidades e pistas oferecidas pelo jogo. Esse jogo foi produzido utilizando o Impress, software destinado a produzir apresentações, disponibilizado pelo sistema operacional Linux.

\subsubsection{Módulo 2: Dialogando}

Nessa etapa, foram desenvolvidas três atividades com o objetivo de fomentar o diálogo e a interatividade entre os aprendizes. Na primeira atividade, os alunos, em grupos, analisaram textos dos seguintes gêneros: poema, história em quadrinhos, fábula, conto, letra de música, notícia e piada. O intuito foi levá-los a perceberem como a narrativa integra os mais variados gêneros textuais. Na segunda atividade, os estudantes, também organizados em grupos, participaram de uma exposição (situação inicial) de uma narrativa para ser desenvolvida colaborativamente, com a participação de todo o grupo na inserção dos demais momentos constitutivos de uma narrativa, até chegarem ao desfecho da história. A equipe que produziu o melhor texto se tornou a vencedora dessa atividade. 
Para a terceira atividade, selecionamos e fragmentamos três narrativas curtas. Os fragmentos foram convertidos em Quick Response Codes ${ }^{2}$, conhecidos como QR Codes, e, depois de impressos, afixados em diversos lugares da escola. Cada equipe de alunos se empenhou na busca pelos códigos espalhados e, utilizando o celular, puderam fazer a leitura de cada fragmento. Posteriormente, os fragmentos foram organizados de maneira a recompor as três narrativas, obedecendo à sequência adequada de cada uma. Por ser uma atividade competitiva, a equipe que primeiro entregou as narrativas organizadas foi considerada vencedora.

\subsubsection{Módulo 3: Refletindo}

As atividades individuais foram priorizadas nesse módulo. Realizamos a análise e reflexão sobre os conhecimentos construídos sobre texto narrativo. Enfatizamos os elementos de narrativa que estão presentes no game "Uma aventura em outro mundo", trabalhado no primeiro módulo, e também discutimos sobre os jogos preferidos de cada estudante, levandoos a refletirem sobre a história que integram tais jogos. Aprofundamos também os estudos sobre os tipos de narradores.

\subsubsection{Módulo 4: Praticando}

A última etapa foi a aplicação prática dos conhecimentos construídos ao longo de todo o processo. Atuando em duplas, os alunos produziram uma narrativa interativa/gamificada utilizando a Plataforma Faz Game ${ }^{3}$, um software on-line que pode ser utilizado gratuitamente por instituições de ensino e usuários independentes para a criação de games educacionais. Foram realizadas algumas oficinas de gamificação para que os estudantes pudessem operar adequadamente os recursos disponibilizados pelo programa. As atividades oportunizaram o estabelecimento de um ambiente de interatividade e cooperação.

No projeto de intervenção desenvolvido, a avaliação esteve ligada ao cumprimento das tarefas e desafios. A cada tarefa ou desafio cumprido, o estudante acumulou pontos. No fim das atividades, os estudantes foram recompensados (com notas), conforme os pontos acumulados ao longo da intervenção. Nas atividades que envolveram competição,

\footnotetext{
${ }^{2}$ Quick Response Codes (QR Codes) são códigos de barras bidimensionais que podem ser convertidos facilmente em informação, por estarem associados a textos, links da internet, localização geográfica, dentre tantas outras possibilidades (NICHELE; SCHLEMMER; RAMOS, 2015). A leitura desses códigos por ser feita por meio de telefone celular equipado com câmera.

${ }^{3}$ Disponível em: <https://www.fazgame.com.br/>.
} 
desenvolvidas em grupo, as equipes cujos textos melhor atenderam à proposta da gamificação foram premiadas com cestas de chocolates.

\section{Resultados}

A pesquisa aqui apresentada está em andamento, em fase de análise de dados, coletados durante a aplicação da proposta de intervenção. Quanto ao progresso na escrita de textos narrativos, não há resultados definitivos; há apenas evidências de que os alunos avançaram, tendo em vista o acompanhamento direto que empreendemos. Como a observação direta do pesquisador faz parte da coleta de dados, podemos afirmar que houve engajamento e participação ativa dos estudantes nas atividades propostas no projeto educacional de intervenção, inclusive evidente interesse em produzir, ler e revisar os próprios textos.

\section{Considerações finais}

Nos últimos tempos, vários setores profissionais, como o empresarial, o de tecnologia e o de treinamento de funcionários, estão utilizando a gamificação como estratégia motivacional. Na sala de aula, a partir do trabalho de intervenção que apresentamos aqui, pudemos constatar que, de fato, a gamificação pode proporcionar maior engajamento dos alunos e motivar a participação deles nas atividades de aprendizagem.

Não consideramos que a gamificação seja a panaceia geral para os problemas da sala de aula; no entanto, é preciso reconhecer que, com os alunos mais envolvidos, investigativos e determinados, a aprendizagem só poderá ser afetada positivamente. Nesse contexto, é importante destacar a relevância do embasamento teórico para o planejamento de atividades gamificadas, pois, conforme afirma Fardo (2013, p. 93), “os elementos dos games são ferramentas valiosas, e utilizá-las requer discernimento, cuidado e conhecimento”.

É preciso ressaltar que, como a nossa proposta consistiu em adotar a estratégia da gamificação aliada à utilização de tecnologias digitais, nos deparamos com algumas dificuldades quanto ao funcionamento dos equipamentos. O maior desafio encontrado foi a péssima qualidade da internet contratada pela escola, que, por ter velocidade baixa e muitas oscilações, atrasou o desenvolvimento das aulas. Para trabalhos dessa natureza, é imprescindível que os recursos oferecidos pela escola sejam de qualidade, uma vez que isso interfere no resultado das atividades planejadas. 


\section{Referências}

BRASIL. Parâmetros Curriculares Nacionais (PCN): $3^{\circ}$ e $4^{\circ}$ ciclos do Ensino Fundamental: Língua Portuguesa. Brasília: MEC/SEF, 1998

BRONCKART, J-P. Atividade de linguagem, textos e discursos. Trad. de A. R. Machado, P. Cunha. 2. ed. São Paulo: EDUC, 2012.

FARDO, M. L. A gamificação como estratégia pedagógica: estudo de elementos dos games aplicados em processos de ensino e aprendizagem. 2013. 104 f. Dissertação (Mestrado em Educação) - Universidade de Caxias do Sul, Caxias do Sul, 2013

KAPP, K. M. The gamification of learning and instruction: case-based methods and strategies for training and education. New York: Pfieffer: John Wiley \& Sons, 2012.

KLEIMAN, A. B. Preciso ensinar o letramento? Não basta ensinar a ler e a escrever? Campinas, UNICAMP/MEC, 2005.

MARCUSCHI, L. A. Produção textual, análise de gêneros e compreensão. 3. ed. São Paulo: Parábola Editorial, 2008

MINAS GERAIS. Secretaria do Estado de Educação. Conteúdo Básico Comum: CBC Português. Educação Básica - Ensino Fundamental ( $6^{\circ}$ ao $9^{\circ}$ ano). Belo Horizonte: SEE, 2008.

NICHELE, A. G.; SCHLEMMER, E.; RAMOS, A. F. QR Codes na Educação em Química. CINTED-UFRGS, Rio Grande do Sul, v. 13, n. 2, p. 1-9, dez. 2015.

PASSARELI, L. M. G. Ensino e correção na produção de textos escolares. São Paulo: Telos, 2012.

ROJO, R.; CORDEIRO, G. S. Gêneros orais e escritos como objeto de ensino: modo de pensar modo de fazer. In: SCHNEUWLY, B.; DOLZ, J. e colaboradores. Gêneros orais e escritos na escola. Trad. de R. Rojo e G. S. Cordeiro. Campinas: Mercado de Letras, 2004. p. 7-16.

SANTOS, C. F. O ensino da escrita na escola: dos tipos aos gêneros. In: ; MENDONÇA, M.; CAVALCANTI, M. C. B. Diversidade textual: os gêneros na sala de aula. Belo Horizonte: Autêntica, 2007. p. 11-26.

SCHLEMMER, E. Gamificação em espaços de convivência híbridos e multimodais: design e cognição em discussão. Revista da FAEEBA - Educação e Contemporaneidade, Salvador, v. 23, n. 42, p. 73-89, jul.-dez. 2014. DOI: http://dx.doi.org/10.21879/faeeba2358-0194.v23.n42.1029.

THORNBURG, D. Campfires in cyberspace: primordial metaphors for learning in the 21st century, 1996. Disponível em: <http://tcpd.org/Thornburg/Handouts/Campfires.pdf $>$. Acesso em: 26 ago. 2015.

VIANNA, Y.; VIANNA, M.; MEDINA, B.; TANAKA, S. Gamification,Inc: como reinventar empresas a partir de jogos. Rio de Janeiro: MJV Press, 2013.

XAVIER, A. C. S. Letramento digital e ensino. In: SANTOS, C. F.; MENDONÇA, M. Alfabetização e letramento: conceitos e relações. Belo Horizonte: Autêntica, 2005. 